\title{
TINJAUAN TATA LETAK (LAYOUT) POSTER ANTI NARKOBA BADAN NARKOTIKA NASIONAL PROVINSI SUMATERA UTARA
}

\author{
Sarah Agatha Siburian ${ }^{1 *}$, Daulat Saragi ${ }^{2 *}$, Syahruddin Harahap $^{3^{*}}$ \\ Program Studi Pendidikan Seni Rupa Jurusan Seni Rupa Fakultas Bahasa dan Seni \\ Universitas Negeri Medan \\ Jl. Willem Iskandar Pasar V Medan Estate, Kec, Percut Sei Tuan, Kab. Deli Serdang, Kode Pos 20371 \\ Sumatera Utara. Indonesia \\ Email: sarahagatha10@gmail.com
}

\begin{abstract}
Abstrak
Poster merupakan media komunikasi hasil dari desain grafis, yang bertujuan menyampaikan informasi pada konsumen hingga mempengaruhi pembaca. Kesatuan elmen dalam poster mempengaruhi hasil desain. Penelitian ini bertujuan untuk mengetahui sejauhmana penerapan elemen-elemen seperti tipografi, warna, layout, kesesuaian gambar/visual yang terdapat pada poster anti narkoba Badan Narkotika Nasional yang ditujukan kepada remaja dan pelajar tahun 2018. Sampel pada penelitian ini ialah seluruh sampel dari populasi yaitu 3 dari 3 poster. Teknik pengambilan sampel dengan sampel jenuh, merupakan teknik pengambilan seluruh anggota populasi. Adapun analisis data yang digunakan dalam penelitian ini adalah deskriptif kualitatif. Hasil temuan penelitian ini menunjukkan bahwa secara keseluruhan desain poster sudah baik dalam penempatan layout pada warna, tipografi, dan gambar. Pemilihan jenis huruf berkaitan dengan tingkat kemudahan untuk dibaca dan ukuran huruf yang digunakan berkaitan pula dengan keterbacaan teks poster. Jenis huruf yang digunakan pada poster disesuaikan dengan tema. Warna yang digunakan dapat memberikan penekanan pada poster sehingga menimbulkan kontras dan alur baca yang tepat. Pemilihan layout yang tepat menonjolkan pusat perhatian/fokus. Kesatuan penerapan keseimbangan simetris, asimetris, memusat dan menyebar. Keselarasan antara tema dengan gambar juga mendukung desain poster. Dalam pemilihan gambar, gambar yang digunakan dapat mengkomunikasikan informasi atau tujuan dari pesan yang ingin disampaikan.
\end{abstract}

Kata Kunci: poster, layout, tipografi, warna.

\begin{abstract}
Poster is a communication media resulting from graphic design, which invites information in consumers to make it easier for readers. The unity of elements in the poster influences the design results. This study discusses how to apply elements such as typography, color, layout, image / visual suitability needed on the National Narcotics Agency anti-drug poster intended for adolescents and students in 2018. The sample of this study is a sample 3 of 3 posters. The sampling technique is saturated sample, with the technique of taking all members. The data analysis used in this research is descriptive qualitative. The findings of this study indicate that poster design is good in laying out layouts on colors, typography, and images. Font selection poster with level read to read and poster letters used. The type of font used on the poster is adjusted to the theme. The colors used can provide contrast to the poster so as to facilitate contrast and proper reading flow. Choosing the right layout choose the center of attention / focus. The unity of application of symmetrical, asymmetrical, centered and diffuse balance. The alignment between the theme and the picture also supports the poster design. In image selection, the image used can communicate information or the purpose of the message to be conveyed.
\end{abstract}

Keywords: poster, layout, typography, color.

\section{PENDAHULUAN}

Media komunikasi merupakan sarana untuk menyampaikan pesan dari komunikator kepada pendengar atau halayak umum. Dalam kehidupan dewasa ini media komunikasi memiliki peranan penting, karena dengan adanya komunikasi kita bisa menerima informasi yang ada di dunia ini dengan akurat, cepat, tepat, efektif dan efisien. Desain grafis merupakan suatu bentuk komunikasi visual dengan menggunakan bahasa rupa, yang disampaikan melalui media berupa desain yang bertujuan menyampaikan informasi pada konsumen, mempengaruhi, hingga 
merubah perilaku target atau konsumen sesuai tujuan yang ingin diwujudkan. Wujud dari desain grafis yaitu: brosur, surat kabar, majalah, tabloid, poster, banner, dan lain-lain.

Poster adalah media publikasi yang terdiri atas tulisan, gambar, ataupun kombinasi antara keduanya, yang diproduksi secara massal. Poster merupakan salah satu produk media komunikasi sebagai promosi, hiburan, dan penyampaian pesan. Secara khusus poster dibedakan berdasarkan desain dan kegunaannya, poster teks, poster propaganda, poster kampanye, poster layanan masyarakat, poster karya seni, poster film, dan lain-lain. Poster layanan masyarakat adalah jenis poster yang penyampaiannya untuk meningkatkan pengetahuan dan kepedulian masyarakat terhadap isu sosial yang diangkat dalam poster.

Banyak lembaga yang mengeluarkan poster sebagai media komunikasi layanan masyarakat, salah satunya Badan Narkotika Nasional (BNN). Berdasarkan informasi yang diperoleh penulis dari Badan Narkotika Nasional Provinsi Sumatera Utara, poster yang menyuarakan gerakan anti narkoba dan penyalahgunaan narkoba telah banyak dikeluarkan sebagai kepedulian Badan Narkotika Nasional (BNN) kepada masyarakat dan sangat berdampak positif karena dapat mencegah melonjaknya angka penggunaan narkoba. Poster yang dikeluarkan BNN ditujukan kepada anak-anak, remaja, pelajar, orang dewasa, dan orang tua. Pertahun BNN mengeluarkan puluhan poster. Poster narkoba yang dibuat oleh BNN merupakan poster yang berisi gerakan anti narkoba, poster ini banyak kita temukan ditempat-tempat umum seperti alun-alun kota, jalan raya, dan sekolah.

Penyalahgunaan narkotika dimasyarakat menunjukkan angka yang sangat tinggi. Merujuk data BNN pada 2014, prevelensi angka penyalahgunaan narkotika di Sumatera Utara dari 9.808.600 jiwa mencapai 3,20 persen atau setara 313.875 jiwa. Sementara pada 2017, prevelensi angka penyalahgunaan narkotika di Sumatera Utara dari 10.137.500 jiwa mencapai 2,53 persen atau setara 256.478 jiwa. Pada 2018, prevelensi angka penyalahgunaan narkotika dikalangan pelajar di 13 ibukota provinsi di Indonesia mencapai angka 3,2 persen atau setara dengan 2,29 juta orang. Dari data yang diperoleh tahun 2014 dan 2017 Sumatera Utara merupakan urutan ketiga setelah DKI Jakarta dan Kalimantan Timur.

Peneliti melihat poster sebagai media komunikasi juga sangat berpengaruh dalam meningkatnya pengguna narkoba dikalangan pelajar. Dimana isi pesan dalam poster tidak tersampaikan pada masyarakat. Dengan ini peneliti melihat adanya kesenjangan dalam desain poster anti narkoba. Penempatan unsur-unsur pada poster kurang tepat. Diantarannya unsur yang mempengaruhi desain poster yaitu tata letak (layout), tipografi dan warna.

Poster yang baik adalah poster yang dapat menarik perhatian. Dalam desain poster semua unsur berperan menentukan keindahan dan menarik perhatian sebuah karya. Maka, dibutuhkan keseimbangan dalam penempatan tata letak (layout), poster harus mampu mengurutkan elemen dimulai dari yang harus dibaca terlebih dahulu, menonjolkan pusat perhatian, seluruh elemen memiliki kesatuan, penerapan keseimbangan. Berikutnya tipografi, pemilihan jenis huruf berkaitan dengan tingkat kemudahan untuk dibaca, ukuran huruf yang digunakan berkaitan dengan keterbacaan. Pemilihan jenis huruf yang berkaitan dengan tema. Warna, warna yang digunakan pada poster harmonis dalam satu kesatuan.

Berdasarkan faktor-faktor yang telah diuraikan, maka poster bergantung pada unsur-unsur didalam poster yaitu tata letak (layout), penempatan dan pemilihan tipografi dan kesesuaian pemilihan warna, kesesuaian antara gambar dengan tema.

\section{KAJIAN TEORI}

\section{Pengertian Desain Komunikasi Visual}

Menurut Anggraini dan Nathalia dalam buku Desain Komunikasi Visual (2018:13) menjelaskan Desain komunikasi visual adalah kemampuan merancang konsep yang matang dengan memberikan solusi terbaik melalui visual. Desain komunikasi visual, mempelajari berbagai macam bentuk, visual, warna, komposisi, cetak animasi, pembuatan video, secara mendetail. Para desainer harus memiliki ide baru, menarik, tepat sasaran, dan tepat guna untuk membuat sebuah karya desain.

\section{Poster}

Istilah "Bentuk" bera Menurut Kartono dalam buku Poster (2014:198) mengatakan Poster adalah lembar pengumuman untuk menyampaikan informasi yang dipasang ditempat umum. Bahasa yang dipergunakan untuk membuat poster harus singkat, padat, menarik dan persuasif. Umumnya poster terdiri dari teks dan elemen visual. Selain itu ada juga poster yang berisi seluruhnya teks atau seluruhnya visual. Pengaplikasiannya dengan ditempel di dinding atau permukaan datar lainnya dengan sifat mencari perhatian. 


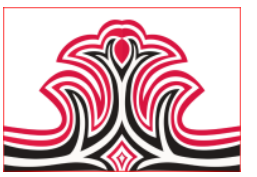

Metode translasi merupakan suatu metode penemuan bentuk baru dengan cara memindahkan bentuk eksisting. Komponen akan dipindahkan ke kanan,ke kiri, ke atas, ke bawah ataupun serong dengan jarak tertentu. Jika menggunakan aturan algoritma, setiap perpindahan akan mempunyai pola atau rumus tertentu. Misal, menggunakan jarak yang sama, turunan kuadrat, rumus kelipatan atau rumus-rumus lainnya.

\section{Tata Letak (Layout)}

Menurut Hendratmandalam buku tips dan trik grafis desain (2015:197)menuliskan: Layoutdalam bahasa Indonesia adalah tata letak atau penempatan. Menurut salah satu teorinya layout adalah usaha untuk menyusun, menata atau memadukan unsur-unsur komunikasi grafis (teks,gambar, tabel,dll) menjadi media komunikasi visual yang komunikatif,estetik dan menarik.

Menurut Rustan (2017:23) bahwa prinsip-prinsip layout dapat dianalogikan sebagai suatu formula untuk membuat suatu layout yang baik. Berikut adalah prinsip-prinsi layout

- Sequence (Urutan)

- Emphasis (Penekanan)

- Balance (Keseimbangan)

- Unity (Kesatuan)

\section{Tipografi}

Menurut Kartono (2015:1) tipografi adalah suatu sarana komunikasi visual yang sangat berarti oleh manusia dan huruf merupakan saksi yang menuliskan dan menceritakan peradaban manusia selaa berabad abad lamanya.

Huruf memiliki klasifikasi berdasarkan latar belakang sejarah perkembangan tipografi yang diambil dari momentum-momentum penting dalam perjalanan sejarah penciptaan dan pengembangan bentuk huruf. Berikut adalah jenis klasifikasi rupa huruf dalam tipografi

- Serif

- San Serif

- Script

- Slab Serif

- Miscellaneous

Tipogarfi sebagai salah satu elemen desain yang mempengaruhi dan dipengaruhi oleh elemen desain lainnya, serta dapat mempengaruhi keberhasilan suatu
Gorga : Jurnal Seni Rupa

Volume 09 Nomor 01 Januari-Juni 2020

p-ISSN: 2301-5942 | e-ISSN: 2580-2380

karya desain secara keseluruhan. Ada 4 hal yang akan menentukan kesuksesan dasain terkait tipografi

- Legibility

- Readibility

- Visibility

- Clarity

\section{Warna}

Menurut Anggraini S dan Kirana (2018:37) warna merupakan unsur yang penting dalam objek desain. Warna merupakan salah satu elemen desain yang mampu menarik perhatian, meningkatkan mood. Warna juga dapat menampilkan identitas atau citra yang ingin disampaikan. Warna dibagi menjadi beberapa kelompok, warna primer, warna sekunder, warna tersier, netral.

Menurut Darmaprawira (2002:25) warna memiliki kontras dalam lingkaran warna, yang dinamakan kontras adalah warna-warna yang dalam lingkaran warna letaknya berhadapan. Adapun beberapa istilah warna berdasarkan tataletak dalam lingkar warna

- Warna analogus

- Warna komplementer

- Warna split komplementer

- Warna triad

\section{Estetis}

Menurut Saragi dalam jurnal Analisis karya lukis seniman wanita sumatera utara ditinjau dari sudut ide (konsep) dan gaya (corak) penampilan karya mengatakan Estetis merupakan suatu seni yang berhubungan dengan nilai estetis. Dalam perkembangan seni masa kini, karya seni juga tidak lagi menjanjikan nilai keindahan. Perkembangan nilai estetsis meliputi banyak hal seperti beauiful (indah), pretty (cantik), chaming (jelita), attractive (menarik) dan masih bayak lagi. Dalam dewasa ini keindahan bukanlah merupakan tujuan yang paling penting dari sebuah karya. Lebih penting mengguncangkan publik dari pada menyenangkan orang dengan karya. Oleh sebab itu nilai estetis pada umumnya diartikan sebagai kemampuan dari sesuatu benda untuk menimbulkan suatu pengalaman estetis.

\section{METODE PENELITIAN}

Penelitian ini dilakukan di kantor Badan Narkotika Nasional Provinnsi Sumatera Utara. Metode penelitian yang dipakai pada penelitian ini adalah kualitatif dan intepretasi. Menurut Sugiyono (2009:4) metode kualitatif sering disebut metode penelitian nauristik karena penelitiannya dilakukan pada kondisi yang alamiah, metode kualitatif menekan kan pada 


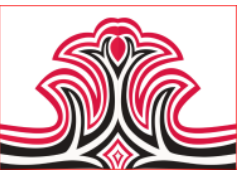

makna, fakta-fakta, penalaran, defenisi, suatu situasi tertentu. Penelitian deskriptif tidak memberikan perlakuan manupilasi atau perubahan pada variablevariabel bebas, tetapi menggambarkan suatu kondisi apa adanya.

\section{HASIL DAN PEMBAHASAN \\ 1.Hasil}

Dalam penelitian ini, peneliti menganalisis desain poster anti narkoba yang dikeluarkan oleh Badan Narkotika Nasional tahun 2018 yang ditinjau dari tata letak (layout), tipografi, warna dan kesesuaian antara gambar dengan tema. Poster yang diteliti berjumlah sebanyak 3 poster, dinilai oleh 2 orang dosen pendidikan seni rupa Universitas Negeri Medan yang berkompeten dibidang desain grafis dan 1 orang praktisi yang juga telah berpengalaman dibidang desain grafis. Hasil penilaian dari penilai guna menunjang hasil penelitian. Poster dianalisis oleh peneliti kemudian diintepretasikan berdasarkan data dan teori mengenai prinsip-prinsip tipografi, warna, layout dan menerangkan data sesuai dengan faktafakta yang ada.

\section{Pembahasan}

\section{1). Poster 1}

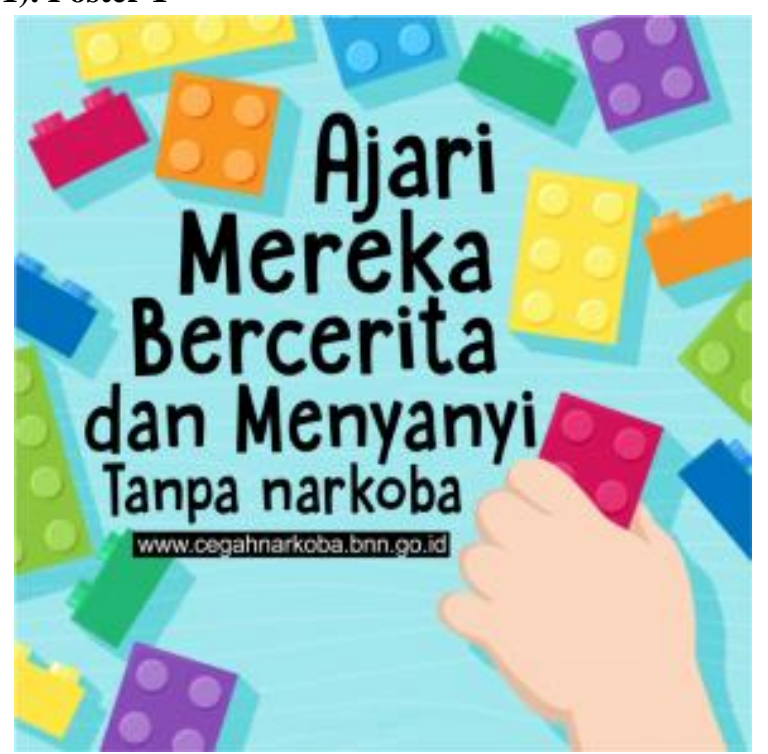

Gambar 1. Ajari Mereka Bercerita dan Menyanyi Tanpa Narkoba (Sumber: Kartono, 2019 : 211)

Layout pada desain poster anti narkoba menggunakan urutan/ alur pembaca (sequence) dari kiri ke kanan dan atas ke bawah. Arah gerak mata pada poster juga dipengaruhi oleh pemberian emphasis pada objek. Salah satu bentuk emphasis dalam poster ini ialah kontras. Kontras pada poster terdapat pada warna dan ukuran yang berbeda. Warna pada teks poster hitam kontras terhadap background biru dan ukuran teks dari besar ke kecil menunjukan arah gerak mata.
Gorga : Jurnal Seni Rupa

Volume 09 Nomor 01 Januari-Juni 2020

p-ISSN: 2301-5942 | e-ISSN: 2580-2380

Keseimbangan pada poster menggunakan keseimbangan asimetris. Tipografi menggunakan klasifikasi huruf san serif. Jenis font terdiri dari sugary pancake dan arial black. Ukuran huruf yang digunakan besar sehingga tingkat kemudahan mata mengenali kerakter/ huruf baik (legibility). Hubungan huruf pada poster antara satu dengan yang lain baik, teks dapat dibaca dengan lancar (readibility). Peletakan huruf pada poster juga tidak terhalang oleh gambar dan warna tulisan yang digunakan kontras dengan background.

Warna pada poster menggunakan warna biru muda sebagai background. Warna-warna lego pada poster ini menggunakan teori harmoni warna analogus. Teori warna analogus, ialah warna yang letaknya bersebelahan atau berdekatan antara warna yang satu dengan warna yang lain. Pada poster kesatuan antara warna, visual, dengan tipografi menjadi satu kesatuan, warna yang digunakan pada poster memberikan penekanan dan kontras antara vigure dan ground (emphasisi).

Kesesuaian gambar dengan tema sangat berpengaruh dalam penyampaian pesan terhadap konsumen. Gambar pada poster tidak mengkomunikasikan isi dari pesan yang akan disampaikan, dimana pesan yang disampaikan bernyanyi dan bercerita tanpa narkoba, poster kurang tepat menggunakan gambar lego sebagai bahasa visual yang mempermudah penyampaian tema.

\section{2).Poster 2}

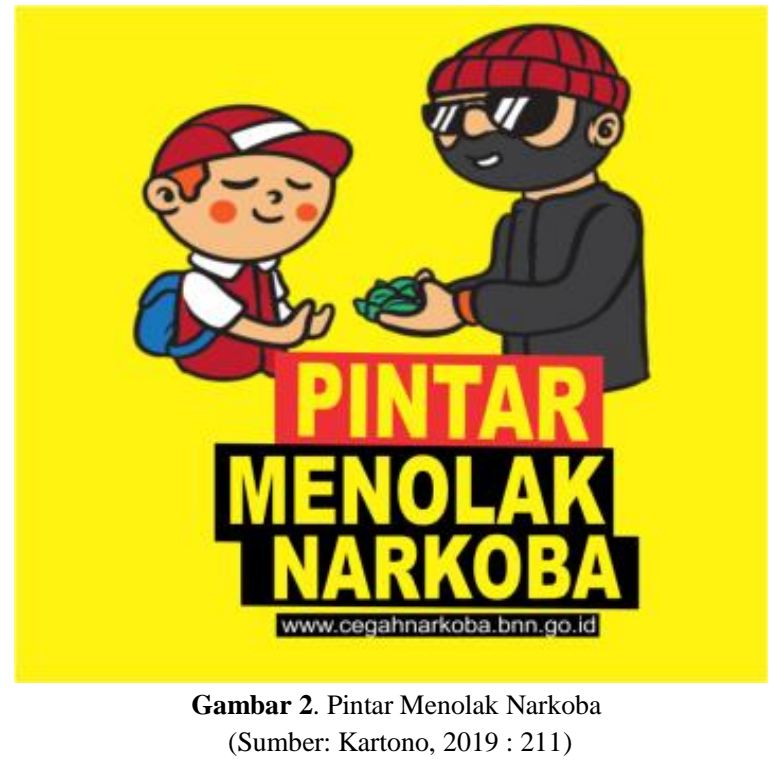

Layout pada desain poster anti narkoba menggunakan urutan/ alur pembaca (sequence) dari kiri ke kanan dan atas ke bawah. Arah gerak mata pada poster juga 
dipengaruhi oleh pemberian emphasis pada objek. Salah satu bentuk emphasis dalam poster ini ialah kontras. Kontras pada poster terdapat pada warna dan ukuran yang berbeda. Warna pada teks poster kuning kontras terhadap namplat yang berwarna hitam dan ukuran tulisan yang besar juga merupakan emphasis. Kontras teks menunjukan arah gerak mata. Keseimbangan pada poster menggunakan keseimbangan simetris. Keseeimbangan simetris merupakan keseimbangan yang dapat terukur secara matematis.

Tipografi menggunakan klasifikasi huruf san serif, dimana pada huruf san serif tidak memiliki sirip pada ujung hurufnya, san serif melambangkan kesederhanaan, lugas, masa kini dan futuristik. Jenis font terdiri dari draf e extra bold dan arial black. Font arial black terdapat pada website Badan Narkotika Nasional. Ukuran huruf yang digunakan besar sehingga tingkat kemudahan mata mengenali kerakter/ huruf baik (legibility), hubungan huruf pada poster antara satu dengan yang lain baik (unity) sehingga teks dapat dibaca dengan lancar (readability), dan peletakan huruf juga tidak terhalang oleh gambar, dan warna tulisan yang digunakan kontras dengan background.

Warna pada desain menggunakan warna kuning sebagai background dan teks, kuning merupakan warna dominan pada poster ini. Menurut teori warna darmaprawira warna kuning memiliki makna kecerdasan, kebahagiaan, sinar kehidupan, ketulusan, kemakmuran. Warna kuning sangat tepat digunakan, dimana warna kuning memiliki makna yang sama dengan pesan slogan pada poster anti narkoba. Warna yang digunakan pada gambar, yaitu merah, hijau yang sangat kontras dengan background. Kesesuaian gambar dengan tema sangat berpengaruh dalam penyampaian pesan terhadap konsumen. Gambar pada poster selaras dengan tema, gambar yang digunakan juga mempermudah penyampaian tema. Gambar pada poster mengkomunikasikan isi dari pesan yang akan disampaikan. Pesan pada poster adalah pintar menolak narkoba sesuai dengan gambar seorang anak menolak diberikan narkoba.

\section{3).Poster 3}

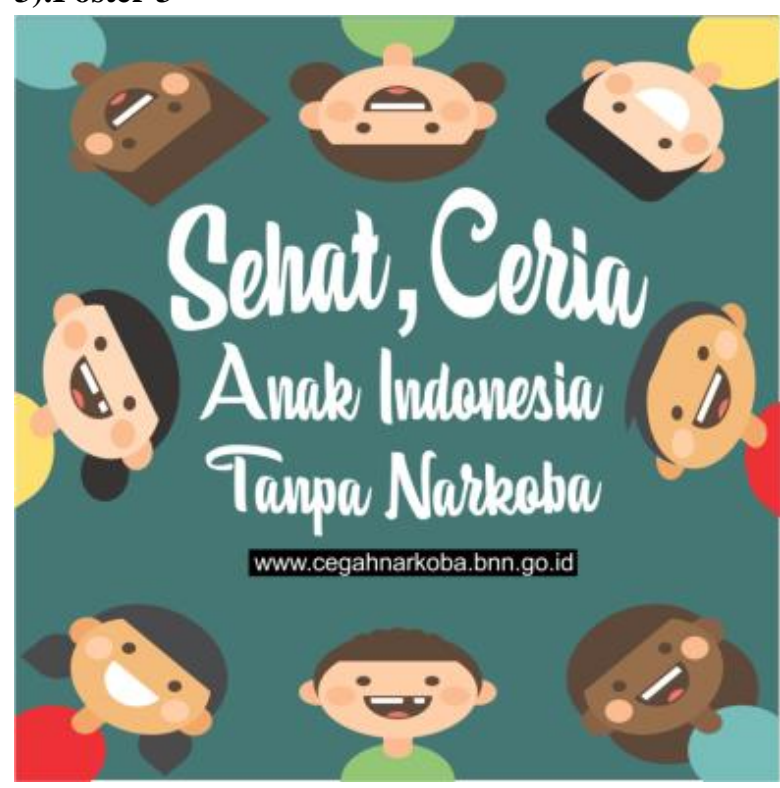

Gambar 3. Sehat, Ceria Anak Indonesia Tanpa Narkoba (Sumber: Kartono, $2019: 211$ )

Layout merupakan hal yang utama dalam desain komunikasi visual. Elemen dan prinsip dalam layout memiliki peran masing-masing dalam membangun keseluruhan layout yang terpadu. Layout pada desain poster anti narkoba menggunakan urutan/ alur pembaca (sequence) dari kiri ke kanan dan atas ke bawah. Arah gerak mata pada poster juga dipengaruhi oleh pemberian emphasis pada objek. Salah satu bentuk emphasis dalam poster ini ialah kontras, kontras pada poster terdapat pada warna dan ukuran yang berbeda. Warna pada teks poster putih kontras terhadap background hijau. Ukuran teks dari besar ke kecil menunjukan arah gerak mata. Keseimbangan pada poster menggunakan keseimbangan simetris.

Keseimbangan simetris pada poster dapat dilihat dari gambar pada poster yang bersifat optis atau seimbang dan dibuktikan dengan tepat secara metematis. Tipografi pada poster menggunakan klasifikasi huruf script. Hutuf script merupakan jenis huruf yang menyerupai goresan tulisan tangan, dan huruf script biasanya miring ke kanan. Font yang digunakan pada teks poster boutiera bold. Pada website Badan Narkotika Nasional menggunakan jenis huruf san serif, font yang digunakan font arial balck. Huruf san serif tidak memiliki sirip pada ujung hurufnya. Ukuran huruf yang digunakan besar sehingga tingkat kemudahan mata mengenali kerakter/ huruf baik (legibility). Hubungan huruf pada poster antara satu dengan yang lain baik (unity), teks dapat dibaca dengan lancar (readability) dan peletakan huruf juga tidak terhalang oleh gambar. 
Warna pada desain poster anti narkoba menggunakan warna hijau sebagai background, menurut teori warna darmaprawira warna hijau memiliki makna alami, ketulusan, kemakmuran, pengharapan. Warna-warna baju anak pada poster ini menggunakan teori harmoni warna analogus. Teori warna analogus, ialah warna yang letaknya bersebelahan atau berdekatan antara warna yang satu dengan warna yang lain. Warna kulit pada gambar juga baik, warna menggambarkan ras Indonesia yang berbeda-beda.Kesesuaian gambar dengan tema sangat berpengaruh dalam penyampaian pesan terhadap konsumen. Gambar pada poster mengkomunikasikan isi dari pesan yang akan disampaikan, dimana pesan yang disampaikan sehat ceria anak Indonesia tanpa narkoba, poster tepat menggunakan gambar anak yang sedang tersenyum yang membentuk membingkai poster sebagai bahasa visual yang mempermudah penyampaian tema

\section{KESIMPULAN DAN SARAN}

\section{Kesimpulan}

Berdasarkan rumusan masalah pemilihan dan penerapan tipografi pada desain poster anti narkoba Badan Narkotika Nasional Provinsi Sumatera Utara sudah baik. Jenis huruf yang digunakan jenis huruf san serif dan script Jenis huruf san serif merupakan jenis huruf yang gampang ditangkap oleh mata karena memiliki ketebalan huruf yang hampir sama, melambangkan kesederhanaan, masa kini dan futuristik. Huruf script, jenis huruf yang menyerupai goresan tulisan tangan. Pemilihan jenis huruf pada poster secara keseluruhan baik. Untuk ukuran teks poster semua sudah sangat baik, tekst dapat dibaca dengan lancar.

Kesatuan antara warna, gambar/ visual, dengan tipografi kontras, secara keseluruhan kontras antara figure dan ground sudah baik. Warna-warna yang digunakan pada poster juga memberikan penekanan antara figure dan ground, warna yang digunakan juga mendukung sesuai dengan tema.

Layout memiliki peran masing masing dalam membangun seluruh poster. Layout pada poster memberikan keseimbangan bagian-bagian poster. Layout pada poster menggunakan alur baca dari kiri ke kanan dan atas ke bawah dengan pola sequence yang berbeda-beda. Arah gerak mata pada poster juga baik, dimana tiap poster memiliki penekanan/ kontras (emphasis).

Keselarasan antara tema dengan gambar poster juga sudah baik, gambar mempermudah penyampaian tema, mengkomunikasikan pesan dan meningkatkan kemenarikan tema. Hanya terdapat 1 poster yang kurang tepat, dimana gambar/ visual yang digunakan tidak sesuai dengan pesan yang akan disampaikan dan pemilihan gambar pada poster.

\section{Saran}

Bagi desainer poster Badan Narkotika Nasional sebaiknya poster lebih divariasikan, dimana desain poster masih sangat standar jika dilihat dari esensi bahaya yang ditimbulkan oleh narkoba. Poster tidak memberikan kesan yang dalam dan tidak memberikan gambaran yang tegas akan bahaya narkoba dan dampak yang ditimbulkan.

Bagi desainer perlu mempedomani elemen-elemen dari prinsip layout, terutama desainer poster Badan Narkotika Nasional agar lebih menyeimbangkan antara prinsip-prinsip layout yang ada pada desain poster. Prinsip layout yang terabaikan bisa menjadi lebih seimbang agar secara keseluruhan desain poster manjadi lebih baik. Dengan harapan penulis, penelitian ini dikembangkan pada ruang lingkup yang lebih luas sehingga dapat membari manfaat yang lebih baik lagi.

Mendesain sebaiknya lebih selektif dalam pemilihan warna yang cocok, disesuaikan dengan tema, dan kepada siapa poster dituju. Dimana setiap warna memiliki makna dan pemahaman yang berbeda-beda.

\section{DAFTAR RUJUKAN}

Anggraini s, Lia dan Kirana Nathalia. (2018). Desain Komunikasi Visual. Bandung: Nuansa Cendikia.

Darmaprawira, Sulasmi. (2002). Warna Teori Kreativitas dan Penggunaannya. Bandung: ITB.

Kartono, Gamal. (2014). Tipografi. Medan: Unimed Perss.

Kartono, Gamal. (2015). Poster. Medan: Unimed Perss.

Rustan, Surianto. (2017). Layout Dasar dan Penerapannya Edisi 2017. Jakarta: PT Gramedia Pustaka Utama.

Saragi, Daulat. (2015). Analisis Karya Lukis Seniman Wanita Sumatera Utara Ditinjau dari Sudut Ide (Konsep) dan Gaya (Corak) Penampilan Karya. Jurnal Bahasa Unimed. ( ), 